\title{
NUEVAS CONSIDERACIONES ACERCA DE LA VIRGEN DE LA EXPECTACIÓN DE CASTILLEJA DE LA CUESTA, UNA OBRA ENCARGADA POR LOS CONDES DUQUES DE OLIVARES
}

\author{
NEW CONSIDERATIONS ABOUT THE "VIRGEN \\ DE LA EXPECTACIÓN" OF CASTILLEJA DE LA CUESTA. \\ A WORK OF ART COMMISSIONED BY \\ THE COUNTS OF OLIVARES
}

\author{
José Manuel Ortega Jiménez \\ Universidad de Alcalá. España \\ ORCID: 0000-0001-7620-4200 \\ joseoj13@gmail.com
}

En 1625 los condes de Olivares encargaron una talla de la Virgen de la Expectación con ocasión del embarazo de su hija María de Guzmán. Esta imagen, de madera policromada y actualmente en la iglesia de Santiago de Castilleja de la Cuesta, fue destinada, en origen, al convento franciscano de los nobles en su villa condal de Olivares (Sevilla). Algunas de sus características, de gran calidad técnica, la aproximan a los modelos cortesanos de la época.

En este artículo, a partir del actual estado de la cuestión, planteamos el nombre de Manuel Pereira como posible autor de la Virgen de la Expectación, un escultor establecido en la Corte que trabajó para importantes nobles de la época, incluyendo los propios Condes Duques.

Palabras clave: Virgen de la Expectación; Castilleja de la Cuesta; III condes de Olivares; Juan de Porres; Manuel Pereira.

In 1625, the Counts of Olivares commissioned a sculpture known as 'Virgen de la Expectación' as a result of their daughter's pregnancy. This sculpture is made of multi-coloured wood and is located in Santiago Church in Castilleja de la Cuesta, Seville. The carving's characteristics are of a high technical quality and similar to some others made in Madrid.

In this article, one renowned sculptor's name is suggested as potential author of 'la Virgen de la Expectación': Manuel Pereira, un artist worked for influential noblemen of the 17th century.

Keywords: Virgen de la Expectación; Castilleja de la Cuesta; III Counts of Olivares; Juan de Porres; Manuel Pereira. 
La escultura de la Virgen de la Expectación, objeto de estudio del presente trabajo, fue realizada en torno a 1625 y enviada al convento franciscano que los condes de Olivares habían fundado en su villa homónima. Esta imagen, de excelente factura, se conoce desde el siglo XVII gracias a la descripción que de ella hiciera Francisco Pacheco en su Arte de la Pintura ${ }^{1}$, y afortunadamente, en la actualidad, se localiza en la iglesia parroquial de Santiago el Mayor de Castilleja de la Cuesta (Sevilla).

Ya desde el siglo XVIII, distintos autores han hecho referencia a la calidad de la imagen. Así en 1724, Francisco de Jesús María señala en sus Crónicas de la Provincia de San Diego que la talla "de rostro encendido con muy proporcionada belleza" se situaba en el altar mayor del convento franciscano de Olivares confirmando, con ello, las palabras de Pacheco ${ }^{2}$.

Será en 1881 cuando José Alonso Morgado realice un primer acercamiento a la historia de la escultura, vinculando su ejecución con el embarazo de María de Guzmán, hija de los Condes Duques de Olivares. Resaltó, además, lo interesante de su iconografía al representar a la Virgen arrodillada con el Niño en el vientre ${ }^{3}$. Una característica esta última que fue señalada también por Manuel Trens en su célebre estudio sobre las imágenes marianas en el Arte Español, publicado en $1947^{4}$.

Sin embargo, no será hasta 1983 cuando Martín Macías atribuya la imagen a un escultor concreto, Francisco de Ocampo, el cual estuvo activo en Sevilla desde finales del siglo XVI. Para el historiador, algunas características como el rostro ovalado, la frente despejada, la mirada baja o el cuello alargado, serían semejantes a otras obras del autor jienense como las Inmaculadas de Comayagua (Honduras). Del mismo modo, señalaba al pintor Lázaro de Pantoja como su policromador ${ }^{5}$.

Aunque sin citar el nombre de ningún artífice, en 1985 se volvía a hacer referencia al origen sevillano de la escultura en el tomo II del Inventario artístico de Sevilla y su provincia, y en este caso tan solo se apunta que es obra de comienzo del siglo XVII ${ }^{6}$.

Siguiendo esa misma línea interpretativa, en 1986 Zahira Véliz realiza una descripción de la talla atendiendo a la calidad de su factura así como a la excepcionalidad de su iconografía. Además, fue la primera autora que relacionó la policromía de la Virgen de la Expectación con la descripción hecha por Francisco Pacheco, atribución aceptada comúnmente por los historiadores ${ }^{7}$.

${ }^{1}$ Pacheco, 1649: 362-363.

2 Jesús María, 1721: 602. La obra se conserva en la Biblioteca Nacional de España (BNE), 1/24191.

3 Alonso Morgado, 1881: 446-453.

4 Trens, 1947: 84.

${ }_{5}^{5}$ Martín Macías, 1983: 152.

${ }^{6}$ Morales/Oliver/Pleguezuelo/Sanz/Serrera/Valdivieso, 1985: 328.

7 Véliz, 1986: 59-32. 
Habrá que esperar a 2002 para tener el primer estudio monográfico dedicado a esta escultura. Lo realizó Amores Martínez. Este sugirió el nombre del artífice castellano Gregorio Fernández como posible autor, aunque consideró que tanto las facciones de la cara como el tratamiento de los paños la aproximaban a los tipos andaluces de la época ${ }^{8}$.

En estos últimos años, la doctora María Cruz de Carlos Varona ha estudiado la escultura en varias ocasiones. Sirviéndose de las fuentes antiguas y de la documentación de archivo, la autora sugiere que la posición arrodillada de la Virgen está en relación con el ceremonial religioso en torno a esta advocación. En la década de los años 20 del siglo XVII aumentó el fervor por la Virgen de la Expectación en la Villa de Madrid, impulsado por el fraile Simón de Rojas. Esto conllevó el encargo de varias tallas de esta devoción, entre las que destacan la imagen que nos ocupa, así como otra, también arrodillada, para la reina Isabel de Borbón, primera esposa de Felipe IV ${ }^{9}$.

A pesar de ello, la falta de documentación ha impedido llegar a conclusiones definitivas sobre el artífice de la Virgen de la Expectación de Castilleja de la Cuesta, y es por esta razón que, teniendo en cuenta el contexto y las circunstancias en torno al encargo de esta imagen, seguidamente realizaremos un nuevo análisis de la talla y aportaremos algunos datos acerca de su posible autoría.

En primer lugar, debemos tener en cuenta que Gaspar de Guzmán hereda el título de III conde de Olivares en marzo de 1607. Si bien nos encontramos ante un linaje de creación reciente, pues su abuelo Pedro de Guzmán recibe dicha distinción en $1535^{10}$, a finales del siglo XVI y, al amparo de la Casa de Austria, la nueva estirpe aumenta su prestigio y ostenta cargos de primer nivel ${ }^{11}$. Así, Enrique de Guzmán, el segundo de los condes y padre de Gaspar, fue nombrado embajador ante la Santa Sede (1582-1591), virrey de Sicilia (1592-1595) y de Nápoles (15951599), y Consejero de Estado ${ }^{12}$. Gracias a los beneficios económicos derivados de estos nombramientos, así como a los importantes réditos de la explotación de sus tierras en el Aljarafe sevillano ${ }^{13}$, la situación económica de la que partió Gaspar de Guzmán tras heredar el mayorazgo fue bastante favorable ${ }^{14}$.

${ }^{8}$ Amores Martínez, 2002: 441.

9 Carlos Varona, 2006: 281-282; 2008: 83-99; 2013: 161; 2018: 185-188.

${ }_{10}$ Archivo Ducal de la Casa de Alba (ADA), C. 295, n 5. Documento citado en Herrera García, 1990: 60.

11 Véase Soria Mesa, 2007: 245.

12 Herrera García, 1990: 71-72.

${ }_{13}$ Herrera García, 1990: 60, 88-96.

${ }_{14} \mathrm{Al}$ dinero recibido por el arrendamiento de distintas casas en la ciudad hispalense, se debe sumar la recaudación por los derechos de alcabalas en villas de la provincia de Sevilla como Albaida o Cantillana y por la explotación ganadera y agrícola de sus tierras del Aljarafe. Archivo Histórico de Protocolos, Madrid (AHPM), prot. 1824, escribano Juan de la Cotera, ff. 863v-882v. Documento citado en Herrera García, 1990: 95 y 99. 
Esto permitió al III conde de Olivares desarrollar, junto a su esposa Inés de Zúñiga con la que contrajo matrimonio en 1607, una importante carrera cortesana que culminó cuando el nuevo monarca Felipe IV le convierte en su primer ministro y le concede la grandeza de España ${ }^{15}$. A partir de este momento los Olivares abordan la continuación de su linaje como afianzamiento de su poder.

Del matrimonio entre Gaspar de Guzmán e Inés de Zúñiga nacieron tres hijos y tan solo su hija María alcanzó la edad adulta ${ }^{16}$. Según Gregorio Marañón, su nacimiento tuvo lugar en Sevilla en 1609 durante el periodo en el que sus padres residieron en la ciudad hispalense (1607-1615) ${ }^{17}$. No tenemos noticias de ella hasta 1622 , momento en el que es nombrada menina de la reina Isabel ${ }^{18}$, siendo además el 10 de octubre de 1624 cuando se firmaron en Madrid las capitulaciones matrimoniales entre María y Ramiro Pérez de Guzmán ante el escribano de la Corte Juan de Santillana ${ }^{19}$. Señala el conde de la Roca que fueron varios los pretendientes de la joven María. Entre ellos destacaron Luis de Haro y el duque de Niebla. Sin embargo, el Conde Duque se decantó por Ramiro Pérez de Guzmán, un noble de segunda fila que pertenecía al linaje castellano de los Guzmán y que ostentaba el título de marqués de Toral $^{20}$. Esta elección puede ser vista como un apoyo de Olivares a los parientes castellanos frente a los andaluces, ramas, ambas, que pugnaban por creerse merecedores de la titularidad de la Casa de Guzmán ${ }^{21}$. Ese mismo día se fundó el mayorazgo de Caravaca o Medina de las Torres, institución dependiente del estado de Olivares y vinculada a sus sucesores que pasarían a denominarse, a partir de ese momento, marqueses de Heliche ${ }^{22}$. Por lo tanto, si el encargo de la talla de la Virgen estuvo vinculado al nacimiento de María de Guzmán, este debemos entenderlo como una alegoría de la futura descendencia del linaje.

Además, esta Virgen se enmarca dentro de las donaciones que los condes de Olivares efectuaron a favor de las órdenes religiosas desde 1607 hasta 1643 a través de una importante política de patronazgo ${ }^{23}$. Con ello, consolidaban su

${ }^{15}$ Gascón de Torquemada, XVII (1991): 92.

16 Martínez Calderón, 1638: 689. Se trata de una obra manuscrita que se localiza en la BNE, mss. 2258.

17 Marañón, 1936 (1980): 276.

${ }_{18}$ Archivo General de Palacio (AGP), sección Reinados, fondo Felipe IV, leg. 8, caja 1, s/f. documento citado en Franganillo Álvarez, 2015: 231.

19 AHPM, prot. 1718, escribano Juan de Santillana, ff. 709r-721v. Documento citado en Herrera García, 1990: 138.

${ }^{20}$ De Vera y Figueroa, 1628: 31-33. Se trata de una obra manuscrita que se localiza en la BNE, mss. 4736.

${ }^{21}$ Elliott, 1986 (2010): 199.

22 AHPM, prot. 1718, escribano Juan de Santillana, ff. 722r-740r. Documento citado en Herrera García, 1990: 141.

${ }^{23}$ Blanco Mozo, 2007: 279-298. 
imagen ante la Corte y disponían de distintas capillas y lugares de enterramiento, siguiendo la costumbre habitual de la nobleza desde el siglo XIII' ${ }^{24}$.

A lo largo de la década de los años 20 del siglo XVII, los Olivares se responsabilizaron del patronazgo de siete instituciones religiosas distribuidas en las provincias de Sevilla y Madrid $^{25}$. Asimismo, impulsaron la fábrica de la iglesia de Santa María de las Nieves de Olivares, que se remontaba a comienzos del siglo XVII y donde se situaría el panteón de la Casa, y llevaron a cabo nuevas fundaciones como el convento dominico de Castilleja de la Cuesta y el franciscano de Olivares, ambos instituidos a principios de 1626.

Precisamente es a este último convento al que los condes de Olivares destinan la imagen escultórica de Nuestra Señora de la Expectación del Parto ${ }^{26}$. La talla, de excelente factura, es de madera policromada y tamaño natural, algo más de un metro de alto. Se representa a María en actitud orante, arrodillada y encinta. Pese a su buen estado de conservación, la talla ha sufrido numerosas modificaciones que han afectado su forma original. De esta manera, se le cortaron los pies para adecuarla a su emplazamiento actual y se sustituyó la imagen del Niño Jesús que se encontraba inserta en su vientre por una de moderna factura ${ }^{27}$.

A través del testimonio de Francisco Pacheco, sabemos que fue tasada en Madrid en 1625 por Eugenio Cajés. Precisamente fue el maestro de Velázquez el que doró y estofó la talla, encargo por el que recibió 2000 reales $^{28}$. El artista nos detalla, de manera pormenorizada, su rica policromía donde sobresalían los tonos azulados, anaranjados y dorados que contrastaban con el encarnado mate de las manos y el rostro ${ }^{29}$. A punta de pincel, realizó la decoración a base de motivos vegetales,

${ }^{24}$ Carmona Carmona, 2017: 19.

25 Blanco Mozo, 2007: 279-282. Se trataba del templo de Nuestra Señora de Loreto en Espartinas (1610), el colegio de Maese Rodrigo de Sevilla, la provincia de San Diego de los Franciscanos Descalzos de Andalucía (1623) la orden de la Santísima Trinidad de Andalucía (1624), el santuario de Nuestra Señora de la Consolación en Utrera, el colegio de Santo Tomás de Aquino en Madrid (1626) y el colegio de San Jorge en la misma villa (1626).

${ }^{26} \mathrm{El}$ convento se situaba en unas casas contiguas al palacio de Olivares. A través de una descripción hecha por el fraile franciscano Francisco de Jesús María, sabemos que el edificio era pequeño y disponía de un oratorio que hacía las funciones de iglesia. Precisamente en el altar de este espacio se situaba la talla de la Virgen de la Expectación. Jesús María, 1724: 599-602. La incomodidad del edificio propició que en 1635 los monjes abandonaran el inmueble y se instalasen en el convento de Castilleja de la Cuesta, cuyas monjas se habían trasladado al monasterio dominico de Loeches (Madrid), la fundación más ambiciosa de los Condes Duques. Prieto Gordillo, 2009: 35.

27 "Virgen de la Expectación; retablo de la Virgen de la Expectación". En: <http:// guiadigital.iaph.es/bien/mueble/214768/sevilla/castilleja-de-la-cuesta/virgen-de-la-expectacion-retablo-de-la-virgen-de-la-expectacion> (28-9-2020).

${ }_{28}$ Pacheco, 1649: 362-363.

${ }^{29}$ Sobre la policromía de Pacheco véase: Gañán Medina, 1999. Hermoso Romero, 2016: 85-101. 
cenefas y anagramas alusivos a María que se distribuían a lo largo del manto y la túnica, y que todavía se pueden apreciar parcialmente. Sin embargo, no quedan restos de las "piedras cuadradas naturales a modo de Diamantes" que se insertaron en la imagen ni de los elementos decorativos como "un Serafin con unos cohollos i flores de punta de pinzel de colores, i el campo de todo ojeteado". Todo esto demostraría que su aspecto original ha sido modificado con el paso de los años (Figura 1$)^{30}$.

Pese a la detallada descripción que ofrece Francisco Pacheco, nada se dice sobre el artífice de la obra. Como ya hemos señalado, su autoría ha sido discutida en diversas ocasiones y se han barajado nombres de artistas prestigiosos de la época sin llegar a una conclusión exacta por falta de documentación. En todo caso, el testimonio de Pacheco no sustentaría la hipótesis de Martín Macías quien, recordemos, atribuía su policromía al pintor Lázaro de Pantoja y fechaba la talla en $1616^{31}$. Tampoco se hace mención a Francisco de Ocampo, escultor al que durante mucho tiempo se ha asignado esta imagen.

Debemos señalar que, dado que la policromía se llevó a cabo en Madrid en 1625 , tal y como señala Pacheco, es razonable pensar que la talla fuera realizada por un artista activo en el entorno cortesano. No tenemos referencias documentales acerca de posibles estancias de Francisco de Ocampo en la Corte. Asimismo, nos parece improbable un envío de la escultura desde Sevilla a Madrid para que Pacheco procediese a su policromado. De hecho, la estancia de este maestro en la villa del Manzanares se prolongó unos meses, ya que en el mismo año de 1625 regresó a la ciudad hispalense ${ }^{32}$.

Si bien algunos elementos formales de la talla pueden asemejarse a obras de Ocampo - como son la cara ovalada, el cuello fino, el tabique de la nariz recto o el pelo ondulado con raya central-, su frontalidad y simetría no corresponden a las imágenes marianas del autor como las ya citadas Inmaculadas de Comayagua, Honduras $^{33}$. De hecho, esas dos últimas características la acercan a modelos marianos de la Corte como veremos en su momento.

En cuanto a la posible autoría de Gregorio Fernández, atribución propuesta por Amores Martínez, creemos que, en caso de que el artífice de la imagen hubiera sido un escultor de tal notoriedad, se hubiera subrayado en el texto de Pacheco, pues así lo hace con el tasador Eugenio Cajés ${ }^{34}$.

A pesar de esto, no sería improbable que los condes de Olivares encargaran alguna obra a Gregorio Fernández. En efecto, Inés de Zúñiga cita en su testamento que había regalado a la condesa de Grajal "el cristo a la coluna de talla que tengo"

${ }^{30}$ Pacheco, 1649: 362-363.

31 Martín Macías, 1983: 152 y 198.

32 Izquierdo Moreno/Páez Morales, 2016: 262.

${ }^{33}$ Sobre las Inmaculadas de Comayagua en Honduras véase: Angulo Iñíguez, 1952: 113-120.

34 Amores Martínez, 2002: 441. 
que podría atribuirse al escultor vallisoletano ${ }^{35}$. En refuerzo de esta opinión, Urrea Fernández indica que realizó varias esculturas para los condes de Olivares, aunque no especifica el nombre de ninguno de estos trabajos ${ }^{36}$. Del mismo modo, en 1631, los Condes Duques se hicieron con el patronazgo del convento abulense de Santa Teresa $^{37}$. Aunque por el momento no hemos localizado ningún documento que lo demuestre, es posible que el valido y su esposa financiaran parte del retablo del altar mayor de la iglesia, ejecutado por Fernández en torno a $1635^{38}$.

Sin embargo, más difícil resulta atribuir la talla de la Expectación a Gregorio Fernández, pues algunas de sus características la alejan de este artífice. Sus Inmaculadas presentan una composición de acentuada simetría por la caída del manto y de los cabellos que enmarcan el rostro y cuya frente queda oculta tras los mechones del flequillo. Las vestimentas son densas y otorgan a la talla solidez y frontalidad que apenas se rompe con un casi inapreciable giro de la cabeza hacia el lado derecho ${ }^{39}$. Por el contrario, en el caso de la Virgen de Castilleja de la Cuesta, sus facciones destacan por su elegancia, armonía y serenidad que comunican al rostro cierta melancolía. Este queda enmarcado por una larga cabellera ondulada con raya en el centro sin flequillo. Por último, los dedos de las manos son menos estilizados que los del artífice castellano y los pliegues de la túnica caen de forma asimétrica suavizando la simetría general de la composición. En definitiva, nos encontramos con una obra de destacada calidad técnica tanto en sus acabados como en su policromía.

En cuanto al posible origen madrileño de la escultura, María Cruz de Carlos Varona señala que durante las primeras décadas del siglo XVII se desarrolló en la villa del Manzanares un profundo fervor por el misterio de la Encarnación y la fiesta de la Expectación del parto de Nuestra Señora. Como apuntamos, su promotor fue el trinitario Simón de Rojas, confesor de la reina Isabel de Borbón, el cual fundó en 1611 la congregación de esclavos del "Dulce Nombre de María" con sede en el convento de la Trinidad de Madrid y a cuya capilla fue destinada una imagen de la Virgen de la $\mathrm{O}$ encargada al escultor Juan de Porres ${ }^{40}$, discípulo de Pompeyo Leoni ${ }^{41}$. Sus características iconográficas se ajustaban a la visión de la Virgen que había presenciado Simón de Rojas ${ }^{42}$. Aunque la escultura ha desaparecido, la

\footnotetext{
${ }_{35}$ AHPM, prot. 6233, escribano Alonso de Velilla, f. 647r-v.

${ }^{36}$ Urrea Fernández, 1984: 99.

37 Martín González, 1976: 306.

38 Sobre este retablo véase Martín González, 1980: 155-156.

39 Véase Hernández Díaz/Martín González/Pita Andrade, 1999.

${ }^{40}$ Carlos Varona, 2008: 83 y 91. Pequeña reseña sobre la historia del convento trinita-
} rio de Madrid en González Dávila, 1623: 251-252.

${ }^{41}$ Martín González, 1983: 250.

42 "Una imagen de Nuestra Señora hermosissima levantados los braços, y las manos abiertas [...] y puestos sus ojos en su Vientre Virginal, que por un cristal claro descubre, y manifiesta al Hijo de sus entrañas [...] en pie, y dando la bendicion”. Arcos, 1670: 333. 
conocemos a través de la estampa que ejecutó Juan Pérez en 1739 y que se conserva en la Biblioteca Nacional de España (Figura 2) ${ }^{43}$.

Por las mismas fechas se realizó otra talla de la misma advocación para el oratorio de la Reina en el Alcázar de Madrid ${ }^{44}$. Aunque por el momento no hemos hallado documentación que lo demuestre, es posible que se encomendara, de nuevo, a Juan de Porres. Este artista tuvo una notoriedad destacable en Madrid y sus alrededores, documentándose su presencia en la catedral de Getafe (Madrid), donde se ocupó de terminar el sagrario del retablo mayor ${ }^{45}$. Del mismo modo, en 1619 la duquesa de Medinaceli le encargó tres retablos y una custodia para la iglesia parroquial y el convento franciscano de la villa de Cogolludo (Guadalajara) ${ }^{46}$. Un artista al que añadimos por nuestra parte una nueva obra a su catálogo. En 1594, fray Domingo de Mendoza le contrata para la realización de una custodia y dos esculturas - una de san Jacinto y otra de la Virgen con el Niño de madera policromada- para el convento dominico de Santo Tomás, situado en la calle Atocha ${ }^{47}$. Por desgracia, la mayor parte de su obra se ha perdido.

Pero centrándonos en el tema que nos ocupa, la continua presencia de este artífice dentro del círculo religioso y de la nobleza de la Corte, pudo favorecer su comunicación con Simón de Rojas. No sería improbable que el fraile trinitario le encomendase la realización de la ya mencionada talla de Nuestra Señora de la Esperanza para el oratorio de Isabel de Borbón en el Alcázar madrileño. Y, como aya de los infantes, la condesa de Olivares debió de tener contacto permanente con el confesor de la reina, por lo que, en consecuencia, también pudo contactar con Juan de Porres y encargarle la realización de la Virgen de Castilleja de la Cuesta.

No obstante, sus características no se ajustan por completo a la descripción ofrecida por el fraile trinitario y que vemos en el aludido grabado, pues a diferencia de la imagen del convento de Madrid, la de Castilleja se le representa arrodillada y en actitud orante, aproximando su iconografía más a la de la Virgen de la Soledad, aquella que desde 1565 se veneraba en Madrid, la cual había sido ejecutada por el escultor Gaspar Becerra para el convento de la Victoria, y cuya fama ayudó a consolidar esta devoción en la Corte ${ }^{48}$. Por ello, no es improbable que los condes de Olivares establecieran como condición que la Virgen de la Expectación de Castilleja de la Cuesta se realizara a partir del modelo establecido por Becerra. Es seguro que

${ }^{43}$ Posteriormente la talla fue enviada a la iglesia de Santa Cruz y al convento de Santo Tomás donde desapareció a causa de un incendio. Corral, 1972: 35.

${ }^{44}$ Carlos Varona, 2006: 281.

45 Bustamante, 1970: 510. No fueron estas las únicas obras de Porres. Bustamante también señala el retablo y un sepulcro en la iglesia madrileña de San Ginés y una talla de san Roque para el consistorio madrileño.

46 Matilla Tascón, 1987: 275.

47 AHPM, prot. 1659, escribano Juan Calvo, ff. 330r-331v.

48 Sánchez de Madariaga, 2008: 220-222. 
Gaspar de Guzmán conocía esta escultura, ya que solía visitar las iglesias de la Villa de manera habitual para pedir favores a las imágenes de su devoción (Figura 3$)^{49}$.

Sin embargo, profundizando en el análisis de la talla de la Virgen de la Expectación, algunas de sus particularidades nos han inclinado a relacionar esta talla con las imágenes marianas de Manuel Pereira. Debemos tener presente que el escultor fue uno de los artífices más prolíficos de la primera mitad del siglo XVII, documentándose su presencia en Madrid desde $1624^{50}$. A partir de este momento, el maestro inicia una carrera profesional en el entorno de la Corte con notable éxito ${ }^{51}$. Sus comitentes fueron, en su mayoría, del ámbito religioso, aunque trabajó al servicio del ayuntamiento de Madrid quien le encomendó la reforma y limpieza de varias fuentes de la Villa ${ }^{52}$. Además, el conde de Olivares pudo conocer al escultor portugués por mediación de los jesuitas, compañía hacia la que sentía una gran estima y algunos de cuyos miembros fueron sus confesores como el padre Juan de Cetina, el padre Salazar o el padre Aguado ${ }^{53}$. De hecho, tenemos constancia documental de la vinculación de los Condes Duques con este artista. En concreto, en 1640, estos le encargaron dos esculturas de piedra de Tamajón - una de santo Domingo y otra de santa Catalina de Siena- para la fachada de la iglesia del convento dominico de Loeches, panteón de la Casa de Sanlúcar ${ }^{54}$. Parece lógico pensar que, al tratarse de su fundación más importante, los Olivares encomendaran este encargo a un artífice que ya hubiera trabajado en alguna ocasión para ellos.

Pero además de estas relaciones históricas, apreciamos similitudes estilísticas entre la Virgen de la Expectación y la imagen de Nuestra Señora del Rosario de la iglesia del Sagrario de Sevilla, obra donada por el arzobispo don Pedro de Tapia y atribuida al escultor portugués (Figura 4) S5 $^{55}$ De hecho, si observamos sus rostros, en ellos se destila cierta melancolía, sentimiento enfatizado con la leve caída de los párpados. La mirada de ambas está dirigida hacia el suelo, contrastando con las cejas ligeramente arqueadas, y los labios de sus bocas están descritos de manera menuda, esbozando una leve sonrisa contenida que dota de expresividad al rostro en ambos casos. Si bien la punta de la nariz y las fosas nasales son más redondeadas en la Virgen de la Expectación, ambas muestran un tabique frontal desde donde arranca una frente recta

${ }^{49}$ BNE, mss. 7692, f. 296v.

${ }^{50}$ En este año de 1624 ejecutó cuatro esculturas en piedra para la fachada de la Compañía de Jesús de Alcalá de Henares. Urrea Fernández, 1977: 258. Agulló y Cobo, 1978: 257.

${ }^{51}$ Sánchez Guzmán, 2008: 19.

${ }^{52}$ Díaz y Díaz, 1976: 49-50. El escultor se encargó de la limpieza de la imagen de Venus que coronaba la fuente de Santo Domingo. También llevó a cabo la realización de una escultura en piedra de Neptuno para la fuente de la plaza del Humilladero.

${ }_{53}$ Marañón, 1936 (1980): 183-184.

54 Agulló y Cobo, 1978: 271.

55 Sánchez Guzmán, 2008: 183-184. 
y despejada. Los cabellos ondulados, con raya central, enmarcan la cara y enfatizan la forma ovalada de la cabeza que se apoya sobre un esbelto cuello cilíndrico. Unas coincidencias que igualmente se repiten, principalmente en las facciones del rostro y en la expresión de tristeza, con la Virgen de la Gracia de la iglesia de San Agustín de la Orotava (Santa Cruz de Tenerife), obra de Pereira datada en $1670^{56}$.

En cuanto a las manos, las de Nuestra Señora del Rosario son algo más finas que las de la Virgen de Castilleja de la Cuesta, aunque apreciamos ciertas semejanzas en la forma cónica y alargada de los dedos. Esta particularidad también se aprecia en la talla de la Concepción del convento de San Esteban de Salamanca, atribuida a Pereira por Urrea (Figura 5) ${ }^{57}$.

Menos similitudes observamos en las vestiduras, compuestas por túnica y manto. Mientras que las de la Virgen de la Expectación acusan una cierta rigidez a través de pliegues rectos sin apenas movimiento, las de la Virgen de la Iglesia del Sagrario son más angulosas y dinámicas. No obstante, debemos recordar que la talla de Castilleja de la Cuesta data de 1625, poco tiempo después del asentamiento de Pereira en Madrid, y quizás por esta razón, dada su reciente llegada a la villa del Manzanares, es posible que el artista portugués tomara como referencia las imágenes marianas de la Corte en las que predominaba la geometría y la frontalidad.

Y si bien no podemos descartar por completo la posible autoría de Juan de Porres, por las naturales reservas ante la falta de documentación, por los razonamientos estéticos expuestos nos inclinamos a pensar que su autor pudo ser Manuel Pereira. Su renombre en la Corte, su vinculación artística comentada con los Condes Duques y las relaciones estilísticas que se aprecian entre la Virgen de Castilleja y las obras conocidas del escultor portugués así parecen indicarlo.

Sea como fuere, de lo que no tenemos duda es de que la talla de la Virgen de la Expectación tuvo que realizarse en Madrid, bien por el propio Manuel Pereira, bien por algún maestro de su entorno próximo en el ámbito cortesano. Una opinión que queda además reforzada por las enormes semejanzas que presenta esta imagen con la Inmaculada Concepción que, por estos mismos años, se envió desde Madrid con destino a la Catedral de Murcia donde aún podemos contemplarla en el trascoro ${ }^{58}$. Del mismo modo, podemos observar semejanzas con otra imagen de la misma advocación, también de factura madrileña, que se ubica en el retablo mayor de la iglesia del Colegio de la Encarnación de Marchena y que data de comienzos del siglo XVII ${ }^{59}$.

Fecha de recepción: 28 de octubre de 2020.

Fecha de aceptación: 2 de mayo de 2021.

\footnotetext{
${ }^{56}$ Sánchez Guzmán, 2008: 132.

57 Urrea Fernández, 1977: 260. Sánchez Guzmán, 2008: 186.

${ }^{58}$ Sánchez-Rojas Fenoll, 1978: 96.

59 Ravé Prieto, 2019: 158.
} 


\section{BIBLIOGRAFÍA}

Agulló y Cobo, Mercedes (1978): "Manuel Pereira: aportación documental”. En: Boletín del Seminario de Estudios de Arte y Arqueología, 44, pp. 257-278.

Alonso Morgado, José (1881): "La imagen de Nuestra Señora en el Misterio de la Expectación llamada generalmente la Virgen de la O venerada en la Parroquia de Santiago, de Castilleja de la Cuesta”. En: VV.AA: Sevilla Mariana. Sevilla: Librería de D.F. de P. González, pp. 446-453, t. I.

Amores Martínez, Francisco (2002): "Una obra de Francisco Pacheco para la Condesa de Olivares". En: VV.AA: Symposium Internacional Alonso Cano y su época, Granada 14-17 de febrero de 2002. Granada: Consejería de Cultura, pp. 437-443.

Angulo Iñíguez, Diego (1952): "Andrés y Francisco de Ocampo y las esculturas de la Catedral de Comayagua". En: Arte en América y Filipinas, 4, pp. 113120 .

Arcos, Francisco de (1670): Primera parte de la vida del V. y Rmo. P. M.Fr. Simon de Roxas [...]. Madrid: Julián de Paredes.

Blanco Mozo, Juan Luis (2007): Alonso Carbonell (1583-1660) arquitecto del Rey $y$ del Conde-Duque de Olivares. Madrid: Fundación Universitaria Española.

Bustamante, Agustín (1970): "Papeletas del arte castellano. Juan de Porres y Giraldo de Merlo en Ávila. El convento de San José”. En: Boletín del Seminario de Estudios de Arte y Arqueología, 36, pp. 507-514.

Carlos Varona, María Cruz de (2006): "Entre el riesgo y la necesidad: embarazo, alumbramiento y culto a la Virgen en los espacios femeninos del Alcázar de Madrid (siglo XVII)". En: Arenal: revista de historia de mujeres, 2, pp. 263290.

(2008): "Una propuesta devocional femenina en el Madrid de comienzos del siglo XVII". En: Carlos Varona, María Cruz de/Civil, Pierre/Pereda, Felipe/ Vincent-Cassy, Cécile (eds.): La imagen religiosa en la Monarquía Hispánica: usos y devociones. Madrid: Casa de Velázquez, pp. 83-99.

(2013): "Giving Birth at the Habsburg Court: Visual and Material Culture". En: Cruz, Anne. J./Galli Estampino, Maria (eds.): Early Modern Habsburg Women. Transnational Contexts, Cultural Conflicts, Dynastic Continuities. London and New York: Routledge Taylor \& Francis Group, pp. 151-173. (2018): Nacer en Palacio. El ritual del nacimiento en la corte de los Austrias. Madrid: CEEH.

Carmona Carmona, Francisco Manuel (2017): "El frustrado proyecto para panteón y sepulcro del duque de Sessa en Baena”. En: Archivo Español de Arte, 357, pp. 19-30.

Díaz y Díaz, María del Sol (1976): "Fuentes públicas monumentales del Madrid del siglo XVII". En: Villa de Madrid: revista del Excmo. Ayuntamiento de Madrid, 53, pp. 39-50. 
Elliott, John [1986 (2010)]: El Conde-Duque de Olivares, el político en una época de decadencia. Barcelona: Crítica.

Franganillo Álvarez, Alejandra (2015): La reina Isabel de Borbón: las redes de poder en torno a su casa (1621-1644). Tesis doctoral. Madrid: Universidad Complutense de Madrid.

Gañán Medina, Constantino (1999): Técnicas y evolución de la imaginería policroma en Sevilla. Sevilla: Universidad de Sevilla.

Gascón de Torquemada, Gerónimo [XVII (1991)]: Gaçeta y nuevas de la corte de España desde el año 1600 en adelante. En: Ceballos-Escalera, Alfonso (ed.). Madrid: Real Academia Matritense de Heráldica y Genealogía.

González Dávila, Gil (1623): Teatro de las grandezas de la Villa de Madrid Corte de los Reyes Católicos de España. Madrid.

Hermoso Romero, Ignacio (2016): "Policromía y pintura decorativa en la obra de Francisco Pacheco”. En: Muñoz Rubio, María del Valme/Cano Rivero, Ignacio (Coords.): Pacheco: teórico, artista, maestro (1564-1644). Sevilla: Junta de Andalucía, Consejería de Cultura, pp. 85-101.

Hernández Díaz, José/Martín González, Juan José/Pita Andrade, José Manuel (1999): "La escultura y la arquitectura españolas del siglo XVII". En: VV.AA: Summa Artis. Historia general del Arte. Madrid: Espasa Calpe, vol. XXVI.

Herrera García, Antonio (1990): El estado de Olivares. Origen, formación y desarrollo con los tres primeros condes (1535-1645). Sevillla: Diputación Provincial de Sevilla.

Izquierdo Moreno, Rocío/Páez Morales, Lourdes (2016): “Cronología”. En: Muñoz Rubio, María del Valme/Cano Rivero, Ignacio. (Coords.): Pacheco: teórico, artista, maestro (1564-1644). Sevilla: Junta de Andalucía, Consejería de Cultura, pp. 257-263.

Jesús María, Francisco de (1724): Libro quinto de la Primera parte de las chronicas de la provincia de San Diego en Andalucia de religiosos descalzos de N[uestro] P[adre] San Francisco. Sevilla: Convento de San Diego.

Marañón, Gregorio [1936 (1980)]: El Conde-Duque de Olivares: la pasión de mandar. Madrid: Espasa-Calpe.

Matilla Tascón, Antonio (1987): Catálogo de documentos notariales de nobles. Madrid: Hidalguía.

Martín González, Juan José (1976): "El convento de Santa Teresa de Ávila y la arquitectura carmelitana”. En: Boletín del Seminario de Estudios de Arte y Arqueología, 42, pp. 305-324.

(1980): El escultor Gregorio Fernández. Madrid: Dirección General del Patrimonio Artístico, archivos y museos, Patronato Nacional de Museos. (1983): Escultura barroca en España 1600-1770. Madrid: Cátedra. 
Morales, Alfredo/Oliver, Alberto/Pleguezuelo, Alfonso/Sanz, María Jesús/Serrera, Juan Miguel/Valdivieso, Enrique (1985): Inventario artístico de Sevilla y su provincia. Sevilla: Ministerio de Cultura, t. II.

Pacheco, Francisco (1649): El Arte de la Pintura su antigüedad y grandezas [...]. Sevilla.

Prieto Gordillo, Juan (2009): La Villa de Castilleja de la Cuesta: Puerta del Aljarafe. Castilleja de la Cuesta: Ateneo de Castilleja de la Cuesta.

Ravé Prieto, Juan Luis (2019): La villa ducal de Marchena. Sevilla: Diputación de Sevilla.

Sánchez de Madariaga, Elena (2008): "La Virgen de la Soledad. La difusión de un culto en el Madrid barroco". En: Carlos Varona, María Cruz de/Civil, Pierre/Pereda, Felipe/Vincent-Cassy, Cécile (eds.): La imagen religiosa en la Monarquía Hispánica: usos y devociones. Madrid: Casa de Velázquez, pp. 219-240.

Sánchez Guzmán, Rubén (2008): “El escultor Manuel Pereira (1588-1683)”. En: Cuadernos de Arte e Iconografía, 33, pp. 6-286.

Sánchez-Rojas Fenoll, María del Carmen (1978): "La Inmaculada del trascoro de la Catedral de Murcia”. En: Murgetana, 53, pp. 95-98.

Soria Mesa, Enrique (2007): La nobleza en la España Moderna. Madrid: Marcial Pons.

Urrea Fernández, Jesús (1977): "Introducción a la escultura barroca madrileña. Manuel Pereira". En: Boletín del Seminario de Estudios de Arte y Arqueología, 43, pp. 253-268.

(1984): Gregorio Fernández. Valladolid: Obra Cultural de la Caja de Ahorros Popular.

Véliz, Zahira (1986): Artists' techniques in Golden Age Spain: six treatises in translation. New York: Cambridge University Press. 


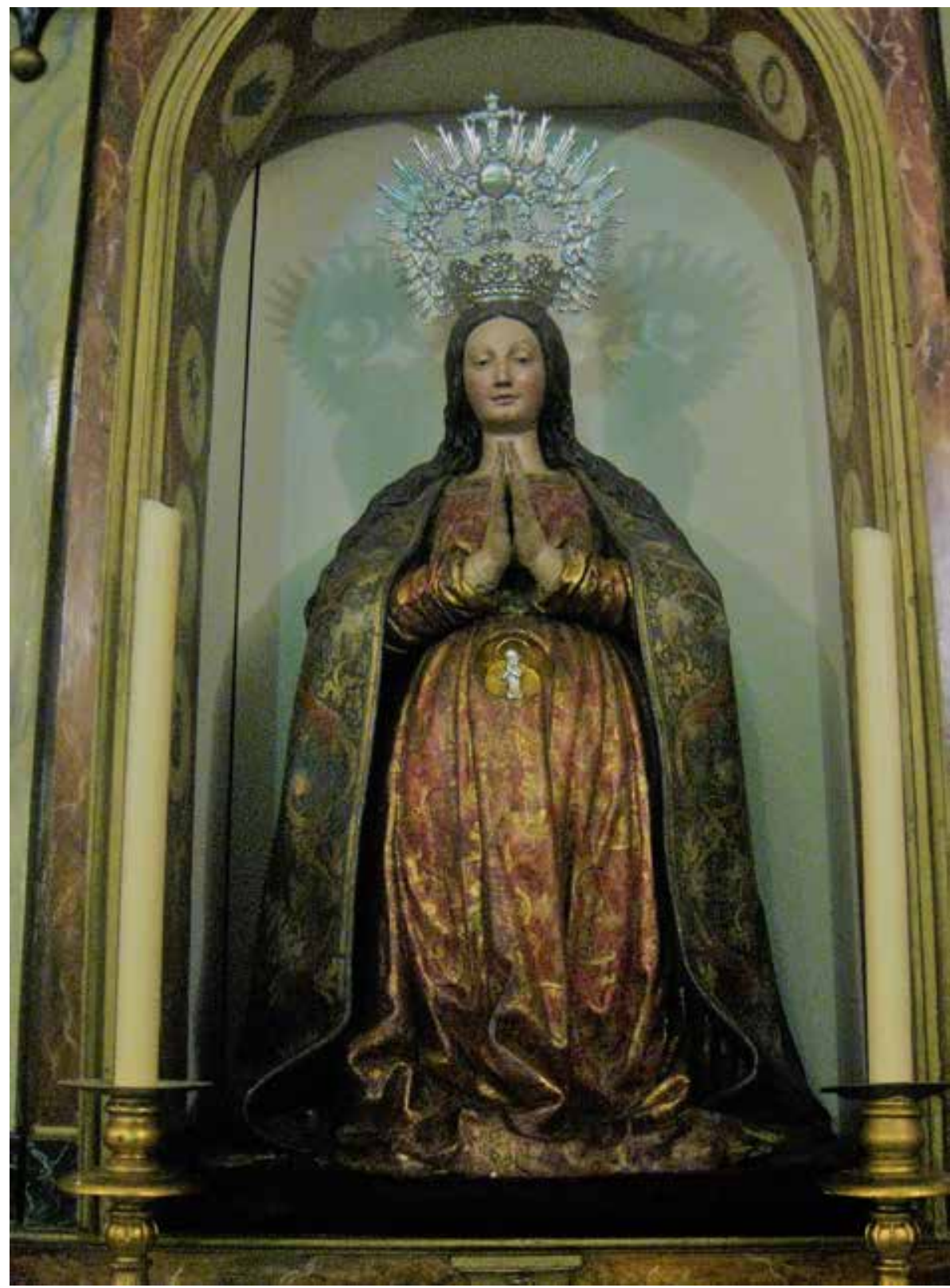

Figura 1. Virgen de la Expectación, siglo XVII, Iglesia parroquial de Santiago el Mayor, Castilleja de la Cuesta (Sevilla). Foto: José Manuel Ortega Jiménez. 


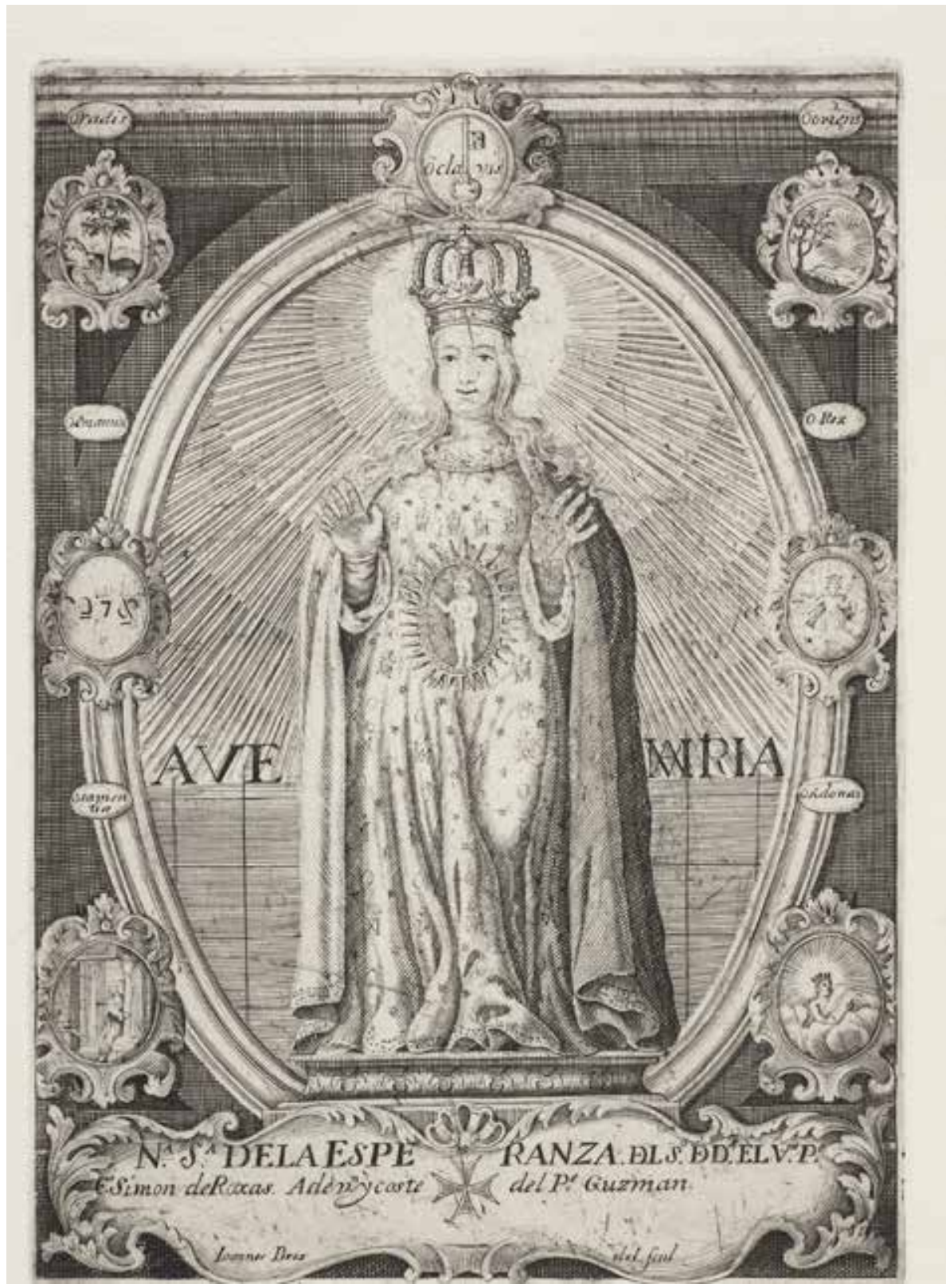

Figura 2. Juan Pérez, Lámina de la Virgen de la Esperanza, 1739, Biblioteca Nacional de España. INVENT/50526. Foto: Biblioteca Nacional de España. 


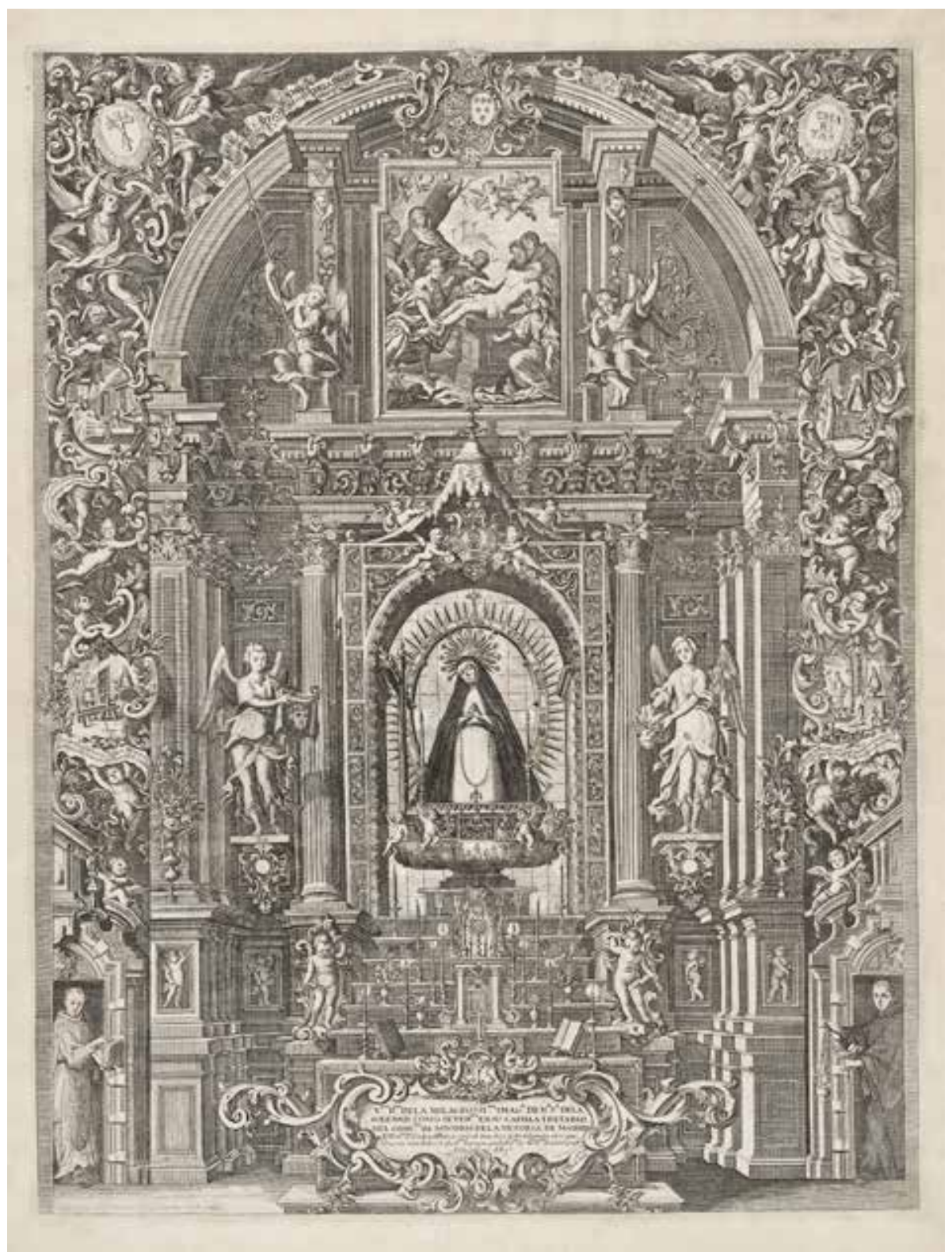

Figura 3. Matías de Irala, Virgen de la Soledad, 1726, Biblioteca Nacional de España. INVENT/14149. Foto: Biblioteca Nacional de España. 


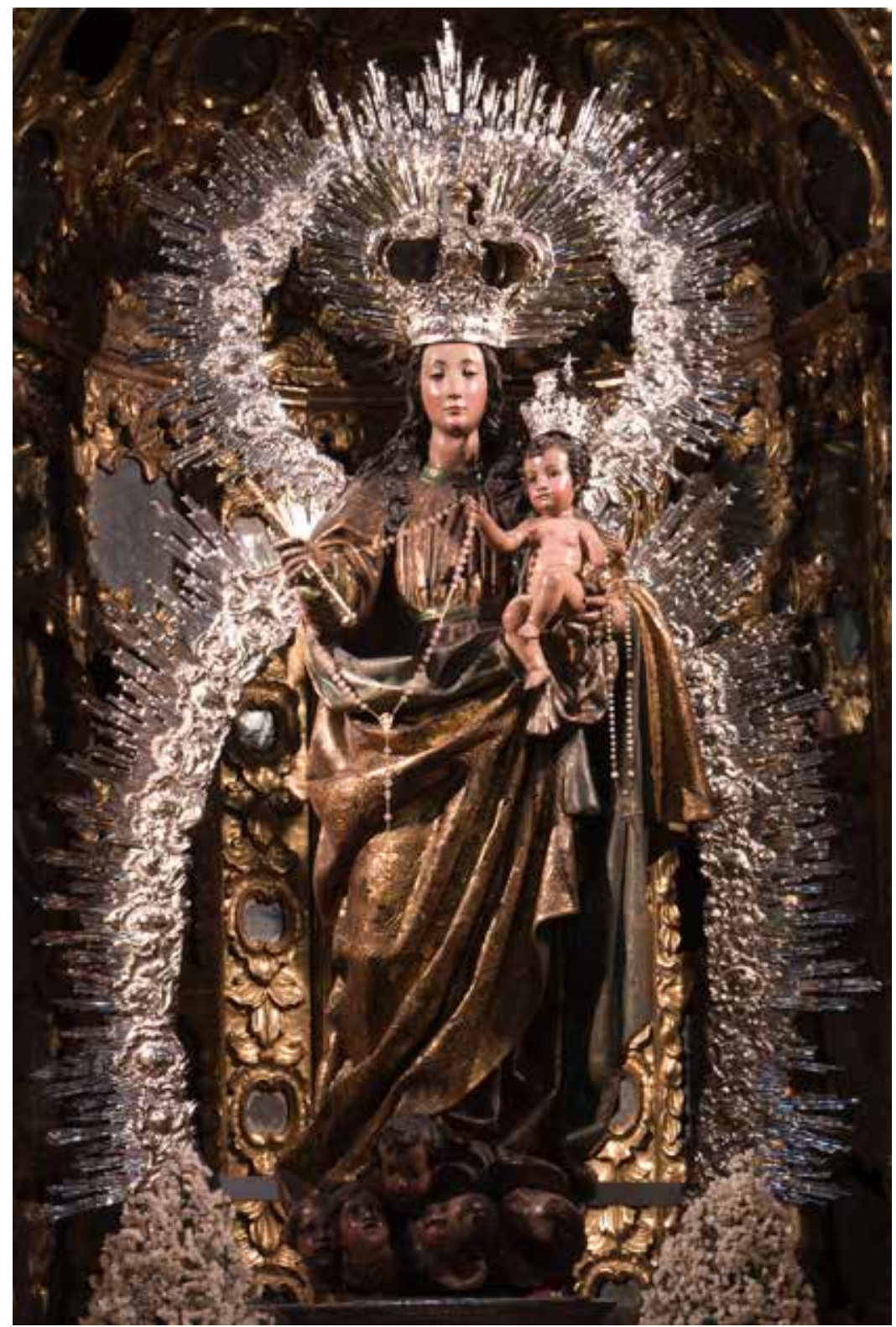

Figura 4. Manuel Pereira (Atrib.), Virgen del Rosario, 1630-1640, Parroquia del Rosario (Sevilla). Foto: Antonio Joaquín Santos Márquez. 


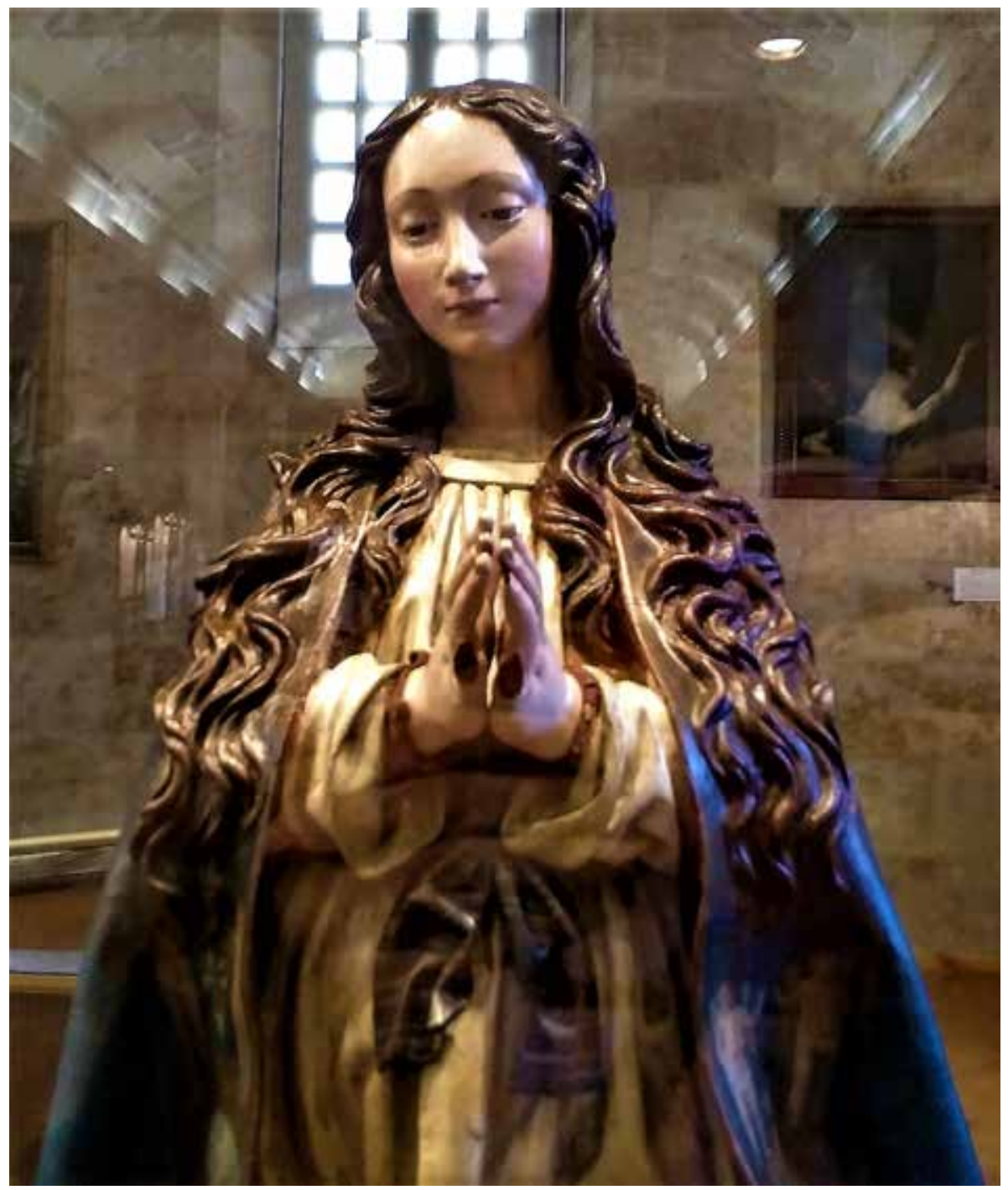

Figura 5. Manuel Pereira (Atrib.), Inmaculada Concepción, 1630-1640, Convento de San Esteban (Salamanca). Foto: José Manuel Ortega Jiménez. 